\title{
Crystal structure of Zika virus NS2B-NS3 protease in complex with a boronate inhibitor
}

Article in Science · July 2016

DOI: 10.1126/science.aag2419

CITATIONS

15

6 authors, including:

\section{Jian Lei}

Universität zu Lübeck

12 PUBLICATIONS 74 CITATIONS

SEE PROFILE

\section{Christoph Nitsche}

Australian National University

22 PUBLICATIONS 246 CITATIONS

SEE PROFILE
READS

59

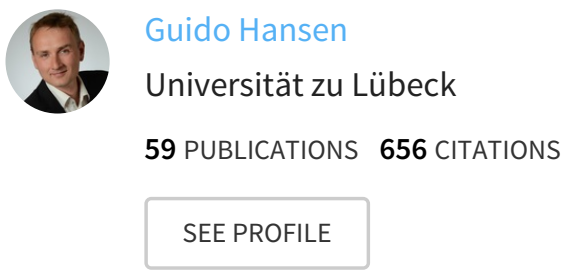




\title{
Crystal structure of Zika virus NS2B-NS3 protease in complex with a boronate inhibitor
}

\author{
Jian Lei, ${ }^{1,2}$ Guido Hansen, ${ }^{1}$ Christoph Nitsche, ${ }^{3 *}$ Christian D. Klein, ${ }^{3}$ Linlin Zhang, ${ }^{1,2}$ Rolf Hilgenfeld ${ }^{1,2} \dagger$ \\ ${ }^{1}$ Institute of Biochemistry, Center for Structural and Cell Biology in Medicine, University of Lübeck, Ratzeburger Allee 160, 23562 Lübeck, Germany. ${ }^{2}$ German Center for \\ Infection Research (DZIF), Hamburg-Lübeck-Borstel-Riems Site, University of Lübeck, Germany. ${ }^{3}$ Medicinal Chemistry, Institute of Pharmacy and Molecular \\ Biotechnology, Heidelberg University, Im Neuenheimer Feld 364, 69120 Heidelberg, Germany.
}

*Present address: Research School of Chemistry, Australian National University, Canberra, ACT 2601, Australia.

†Corresponding author. Email: hilgenfeld@biochem.uni-luebeck.de

The ongoing Zika virus (ZIKV) outbreak is linked to severe neurological disorders. ZIKV relies on its NS2B/NS3 protease for polyprotein processing; hence, this enzyme is an attractive drug target. The $2.7 \AA$ crystal structure of ZIKV protease in complex with a peptidomimetic boronic-acid inhibitor reveals a cyclic diester between the boronic acid and glycerol. The P2 4-aminomethylphenylalanine moiety of the inhibitor forms a salt-bridge with the non-conserved Asp ${ }^{83}$ of NS2B, lon-pairing between Asp ${ }^{83}$ and the P2 residue of the substrate likely accounts for the enzyme's high catalytic efficiency. The unusual dimer of the ZIKV protease:inhibitor complex seen in the crystal may provide a model for assemblies formed at high local concentrations of protease at the endoplasmatic reticulum membrane, the site of polyprotein processing.

Previously considered a rare and mild pathogen for humans (1), Zika virus (ZIKV) infection has recently been found to be responsible for neurological disorders in a significant portion of patients. The infection can trigger Guillain-Barré syndrome (2) and prenatal ZIKV infection is responsible for a dramatically increased number of microcephaly cases in fetuses and newborn children (3). The World Health Organization (WHO) recently declared the association of ZIKV infection with these neurological disorders a Public Health Emergency of International Concern (4). There are no vaccines or antiviral drugs available for protection from or treatment of ZIKV infection.

ZIKV is a member of the genus Flavivirus in the Flaviviridae family of RNA viruses. Its $\sim 10.7$-kb single-stranded RNA genome of positive polarity encodes a single polyprotein, which, by analogy to other flaviviruses, is assumed to be cleaved by host-cell proteases (signalase, furin) and the viral NS2B/NS3 protease into three structural (C, prM/M, and E) and 7 non-structural proteins (NS1, NS2A, NS2B, NS3, NS4A, NS4B, NS5) (fig. S1). Similar to other flavivirus proteases such as those of dengue virus (DENV) and West Nile virus (WNV), the mature form of ZIKV protease consists of the N-terminal domain of NS3, which carries the catalytic triad $\mathrm{Ser}^{135}-\mathrm{His}^{51}-\mathrm{Asp}^{75}$, and the membrane-bound NS2B (see fig. S2 for a sequence alignment). Crystallization of this complex has not been successful so far for any flavivirus protease, but it has been shown that a construct comprising $\sim 40$ hydrophilic residues of NS2B and $\sim 185$ residues of NS3, covalently linked via a $\mathrm{Gly}_{4}-\mathrm{Ser}_{-} \mathrm{Gly}_{4}$ sequence, displays strong peptidolytic activity (5). Crystal structures of the free form of this protease construct ("NS2B-NS3 $3^{\text {pro") }}$ usually reveal an "open conformation" featuring a wellordered NS3 $3^{\text {pro }}$ core and a flexible NS2B part that shows only limited interaction with $\mathrm{NS}^{\text {pro }}$, whereas inhibitor (and presumably substrate) binding induces a pronounced conformational change of NS2B yielding a more compact, "closed" form $(6,7)$.

We expressed in E. coli a DNA construct corresponding to the NS2B-NS3 ${ }^{\text {pro }}$ coding region of the Brazilian ZIKV isolate BeH823339 (8) (GenBank accession number KU729217.2). This construct codes for residues 49 - 95 of ZIKV NS2B, the $C$ terminus of which is covalently linked via $\mathrm{Gly}_{4}-\mathrm{Ser}_{-\mathrm{Gly}}$ to the N terminus of the NS3 (residues 1 to 170). The recombinant enzyme obtained is a mixture of monomer, disulfide-linked dimer (here designated "SSdimer"), and-to a lesser extent-higher oligomers (fig. S3). The double mutant $\mathrm{Cys}^{80} \mathrm{Ser} / \mathrm{Cys}^{143} \mathrm{Ser}$ leads to loss of the disulfide bond, which occurs between $\mathrm{Cys}^{143}$ residues of different polypeptide chains, as revealed by the x-ray structure. The SS-dimer and the monomer obtained by reduction with tris(2-carboxyethyl)phosphine (TCEP) (fig. S3) as well as the $\mathrm{CyS}^{80} \mathrm{Ser} / \mathrm{Cys}^{43} \mathrm{Ser}$ mutant of ZIKV NS2B-NS3 ${ }^{\text {pro }}$ are hyperactive against the standard flavivirus protease substrate benzoyl-norleucine-lysine-lysine-arginine 7-amino-4methylcoumarine (Bz-Nle-Lys-Lys-Arg-AMC), with a very low $K_{\mathrm{m}}$ and a $k_{\text {cat }} / K_{\mathrm{m}}$ more than 20-times higher than for the WNV enzyme (Table 1 ).

In order to elucidate the molecular basis of this hyperactivity, and to provide a starting point for structure-based drug design efforts, we have crystallized ZIKV NS2B-NS3 ${ }^{\text {pro }}$ 
in the closed form and determined its X-ray structure at 2.7 $\AA$ resolution. Containing two molecules (A and B) per asymmetric unit of the crystal, the structure reveals the same chymotrypsin-like fold for the NS3 $3^{\text {pro }}$ domain as seen previously for other flavivirus proteases, with the NS2B polypeptide wrapped around the $\mathrm{NS}^{\text {pro }}$. The interaction between the two is stabilized by hydrogen bonds between $\beta$ strands $\beta 1$ and AI, $\beta 2$ and BIIa, as well as $\beta 3$ and BIIb of NS2B and NS3 $3^{\text {pro }}$, respectively (Fig. 1A). The r.m.s. deviations between the ZIKV NS2B-NS3 ${ }^{\text {pro }}$ complex and tetrapeptide aldehyde complexes of WNV and DENV-3 proteases are 0.9 - $1.1 \AA$ [for main-chain atoms; PDB codes 2FP7 and 3U1I (6, 9)]. The capped dipeptide boronic-acid compound cn-716 (Fig. 1C) was used to obtain the closed conformation of the protease. We found this compound to reversibly inhibit ZIKV NS2B-NS3 ${ }^{\text {pro }}$ with $\mathrm{IC}_{50}=0.25 \pm 0.02 \mu \mathrm{M}$ and $K_{\mathrm{i}}=0.040$ $\pm 0.006 \mu \mathrm{M}$ (in the presence of $20 \%$ glycerol, fig. S4). In the structure of the complex, the boron atom is covalently linked to the side-chain $\mathrm{O} Y$ of the catalytic Ser135 (Fig. 1, B and $\mathrm{D}$ to $\mathrm{F}$ ). The structure also reveals that the boronic acid moiety forms a cyclic diester with glycerol, which was continuously present in our enzyme preparation during purification and crystallization, as well as cryoprotection of crystals. Boronic acids tend to form esters with diols and triols, especially if 5- or 6-membered rings can be formed (10). Our $\mathrm{F}_{\mathrm{o}}-\mathrm{F}_{\mathrm{c}}$ difference density indicates that a sixmembered ring has been formed by reaction of the boronic acid with the terminal hydroxyl groups of glycerol (Fig. 1, B and $\mathrm{D}$ to $\mathrm{F}$ ). The six-membered ring fits neatly into the $\mathrm{S1}^{\prime}$ pocket of the enzyme (Fig. 1B), a site so far rarely addressed by synthetic flavivirus protease inhibitors. In the absence of glycerol, the $\mathrm{IC}_{50}$ for the boronic acid inhibitor was nearly unchanged $(0.20 \pm 0.02 \mu \mathrm{M})$, but we note that through ester formation with larger, more hydrophobic diols or triols, a prodrug might be obtained that will traverse the cellular membrane more readily than free boronic-acid derivatives.

Due to the ring closure, the tetrahedral geometry of the boron is somewhat distorted. In molecule $\mathrm{A}$, the 6membered ring assumes a boat-like conformation, with the middle hydroxyl group (O2) of glycerol in an axial position and donating an intramolecular hydrogen bond to the mainchain oxygen of the $\mathrm{P} 2$ residue of the inhibitor (Fig. 1E). In molecule $\mathrm{B}$, the 6-membered ring adopts a somewhat twisted half-chair conformation and the central hydroxyl group, also in an axial position, donates a hydrogen bond to the carbonyl oxygen of $\mathrm{Val}^{36}$ (Fig. $\mathrm{IF}$ ). In molecule $\mathrm{A}$, the two ring oxygens ( $\mathrm{O} 1$ and $\mathrm{O} 3$ ) accept $\mathrm{H}$-bonds respectively from the amide of $\mathrm{Gly}^{133}$, i.e., from the oxyanion hole, and from the catalytic $\mathrm{His}^{51}$, whereas the latter interaction is missing in molecule B. These differences between the two inhibitor molecules in the asymmetric unit of the crystal reflect the conformational variability of the cyclic boronates (10).
The P1-Arg residue of cn-716 forms a salt-bridge with Asp $^{129}$, a feature conserved in many flavivirus protease complexes. Most probably protonated, the amino group of the 4aminomethyl-phenylalanyl residue in the P2 position forms a hydrogen bond with the main-chain oxygen of $\operatorname{Ser}^{81 *}$ and a salt-bridge with $\mathrm{Asp}^{83 *}$ of the NS2B polypeptide (Fig. 1B; residues of NS2B are denoted by *). Asp ${ }^{83 *}$ is Asn in WNV and Ser or Thr in DENV 1-4 NS2B-NS3 ${ }^{\text {pro }}$ (fig. S2), i.e., unable to form an ion-pair interaction with the $\mathrm{P} 2$ residue of the inhibitor or the substrate, Bz-Nle-Lys-Lys-Arg-AMC. The Asp $^{83 *}$ Asn mutation leads to a $\sim 2$-fold increase of $K_{\mathrm{m}}$ and a $k_{\text {cat }} / K_{\mathrm{m}}$ reduced by $55 \%$, compared to WT enzyme (Table 1 ). The Asp residue in this position provides an at least partial explanation for the significantly lower $K_{\mathrm{m}}$ and hence, the much higher $k_{\text {cat }} / K_{\mathrm{m}}$ of ZIKV protease compared to the WNV and DENV enzymes (Table 1). DENV NS2B/NS3 protease has been shown to counteract the type-I interferon response via digesting the stimulator of inferon genes (STING) in human dendritic cells (DCs) (11). As ZIKV also permissively infects human DCs (12), we speculate that an increased catalytic activity of ZIKV NS2B/NS3 ${ }^{\text {pro }}$ could cause more efficient cleaveage of STING, thereby leading to an enhanced suppression of the host innate immunity.

In the crystal, ZIKV NS2B-NS3 ${ }^{\text {pro }}$ forms an unusual dimer with non-crystallographic, quasi-twofold symmetry (Fig. 2A) that has not been seen with other flavivirus proteases. This tight dimer has to be distinguished from the labile SS-dimers seen in solution (see above). In the tight dimer, the substrate-binding sites of the two monomers, along with the bound inhibitor, face each other (Fig. 2B). The dimer has openings at both sides, which upon some "breathing" would allow access of substrate to the two active sites located at the center (Fig. 2A). The tight dimer in the asymmetric unit of the crystal is connected to neighboring dimers through two labile disulfide bonds linking $\mathrm{Cys}^{143}$ of monomer A to the same residue of monomer B in a symmetry-related dimer, and vice versa, giving rise to disulfidemediated polymers of tight dimers $\left(\mathrm{Cys}^{143}\right.$ is indicated in Fig. $2 \mathrm{~A})$. This disulfide bond is responsible for the formation of the "SS-dimer" apparent in the SDS-PAGE (fig. S3). After a few seconds of the crystal in the x-ray beam, this exposed disulfide appears to be reduced as a consequence of irradiation, although the presence of the disulfide seems to be essential for crystallization of the ZIKV NS2B-NS3 ${ }^{\text {pro }}$, as we failed to obtain crystals of the $\mathrm{Cys}^{80} \mathrm{Ser} / \mathrm{Cys}^{143} \mathrm{Ser}$ variant.

Formation of the tight dimer in the asymmetric unit buries $\sim 1240 \AA^{2}$ of the surface of each of the two monomers and the shape complementarity $(S c)$ index (13) is 0.64 [for a large set of well-characterized homodimeric proteins, the mean $S c$ was $0.69 \pm 0.07$; (14)]. If we include the two inhibitor molecules in the calculation, $\sim 1500 \AA^{2}$ of molecular surface are buried per monomer. Both the large surface area 
buried and the shape complementarity indicate that dimer formation is likely of biological relevance. Although we failed to observe this dimer in solutions of the ZIKV NS2B$\mathrm{NS}^{\text {pro }}$ complex with cn-716 up to a concentration of 133 $\mu \mathrm{M}$, we detected it by electrospray ionization (ESI) mass spectrometry in the presence but not in the absence of the boronic acid inhibitor (fig. S6). The structure suggests that the closed form of the enzyme has the potential of forming well-defined dimers at higher concentrations, as they may occur (and perhaps be promoted by the membraneembedded parts of NS2B which are lacking in the present structure) at the endoplasmic reticulum membrane where polyprotein processing and viral replication take place.

Peptide boronic acids have previously been tested as drugs, and the proteasome inhibitor bortezomib (Velcade) has been approved for the treatment of multiple myelomas (15). A tetrapeptide-boronic acid was reported as a potent inhibitor of the DENV-2 NS2B-NS3 ${ }^{\text {pro }}$, but not studied further (16). Peptide boronic acids are usually not cytotoxic to Huh7 cells, which is what we observe with compound cn716 (fig. S7). The structure presented here forms a good starting point for the design of more specific anti-ZIKV drugs.

\section{REFERENCES AND NOTES}

1. W. G. Bearcroft, Zika virus infection experimentally induced in a human volunteer. Trans. R. Soc. Trop. Med. Hyg. 50, 442-448 (1956). Medline doi:10.1016/00359203(56)90090-6

2. V. M. Cao-Lormeau, A. Blake, S. Mons, S. Lastère, C. Roche, J. Vanhomwegen, T. Dub, L. Baudouin, A. Teissier, P. Larre, A. L. Vial, C. Decam, V. Choumet, S. K. Halstead, H. J. Willison, L. Musset, J. C. Manuguerra, P. Despres, E. Fournier, H. P. Mallet, D. Musso, A. Fontanet, J. Neil, F. Ghawché, Guillain-Barré Syndrome outbreak associated with Zika virus infection in French Polynesia: A case-control study. Lancet 387, 1531-1539 (2016). Medline doi:10.1016/SO1406736(16)00562-6

3. S. A. Rasmussen, D. J. Jamieson, M. A. Honein, L. R. Petersen, Zika virus and birth defects-Reviewing the evidence for causality. N. Engl. J. Med. 374, 1981-1987 (2016). Medline doi:10.1056/NEJMsr1604338

4. D. L. Heymann, A. Hodgson, A. A. Sall, D. O. Freedman, J. E. Staples, F. Althabe, K. Baruah, G. Mahmud, N. Kandun, P. F. Vasconcelos, S. Bino, K. U. Menon, Zika virus and microcephaly: Why is this situation a PHEIC? Lancet 387, 719-721 (2016). Medline doi:10.1016/S0140-6736(16)00320-2

5. D. Leung, K. Schroder, H. White, N. X. Fang, M. J. Stoermer, G. Abbenante, J. L. Martin, P. R. Young, D. P. Fairlie, Activity of recombinant dengue 2 virus NS3 protease in the presence of a truncated NS2B co-factor, small peptide substrates, and inhibitors. J. Biol. Chem. 276, 45762-45771 (2001)._Medline doi:10.1074/jbc.M107360200

6. P. Erbel, N. Schiering, A. D’Arcy, M. Renatus, M. Kroemer, S. P. Lim, Z. Yin, T. H. Keller, S. G. Vasudevan, U. Hommel, Structural basis for the activation of flaviviral NS3 proteases from dengue and West Nile virus. Nat. Struct. Mol. Biol. 13, 372-373 (2006). Medline doi:10.1038/nsmb1073

7. D. Luo, S. G. Vasudevan, J. Lescar, The flavivirus NS2B-NS3 protease-helicase as a target for antiviral drug development. Antiviral Res. 118, 148-158 (2015). Medline doi:10.1016/j.antiviral.2015.03.014

8. N. R. Faria, R. S. Azevedo, M. U. Kraemer, R. Souza, M. S. Cunha, S. C. Hill, J. Thézé, M. B. Bonsall, T. A. Bowden, I. Rissanen, I. M. Rocco, J. S. Nogueira, A. Y. Maeda, F. G. Vasami, F. L. Macedo, A. Suzuki, S. G. Rodrigues, A. C. Cruz, B. T. Nunes, D. B. Medeiros, D. S. Rodrigues, A. L. Nunes Queiroz, E. V. da Silva, D. F. Henriques, E. S. Travassos da Rosa, C. S. de Oliveira, L. C. Martins, H. B. Vasconcelos, L. M. Casseb, D. B. Simith, J. P. Messina, L. Abade, J. Lourenço, L.
Carlos Junior Alcantara, M. M. de Lima, M. Giovanetti, S. I. Hay, R. S. de Oliveira, P. S. Lemos, L. F. de Oliveira, C. P. de Lima, S. P. da Silva, J. M. de Vasconcelos, L. Franco, J. F. Cardoso, J. L. Vianez-Júnior, D. Mir, G. Bello, E. Delatorre, K. Khan, M. Creatore, G. E. Coelho, W. K. de Oliveira, R. Tesh, O. G. Pybus, M. R. Nunes, P. F. Vasconcelos, Zika virus in the Americas: Early epidemiological and genetic findings. Science 352, 345-349 (2016)._Medline doi:10.1126/science.aaf5036

9. C. G. Noble, C. C. Seh, A. T. Chao, P. Y. Shi, Ligand-bound structures of the dengue virus protease reveal the active conformation. J. Virol. 86, 438-446 (2012). Medline doi:10.1128/JVI.06225-11

10. L. Türker, Some boric acid esters of glycerol - An ab initio treatment. Indian J. Chem. 45A, 1339-1344 (2006).

11. S. Aguirre, A. M. Maestre, S. Pagni, J. R. Patel, T. Savage, D. Gutman, K. Maringer, D. Bernal-Rubio, R. S. Shabman, V. Simon, J. R. Rodriguez-Madoz, L. C. Mulder, G. N. Barber, A. Fernandez-Sesma, DENV inhibits type I IFN production in infected cells by cleaving human STING. PLOS Pathog. 8, e1002934 (2012). Medline doi:10.1371/journal.ppat.1002934

12. R. Hamel, O. Dejarnac, S. Wichit, P. Ekchariyawat, A. Neyret, N. Luplertlop, M. Perera-Lecoin, P. Surasombatpattana, L. Talignani, F. Thomas, V. M. CaoLormeau, V. Choumet, L. Briant, P. Desprès, A. Amara, H. Yssel, D. Missé, Biology of Zika virus infection in human skin cells. J. Virol. 89, 8880-8896 (2015). Medline doi:10.1128/JVI.00354-15

13. M. C. Lawrence, P. M. Colman, Shape complementarity at protein/protein $\begin{array}{llllll}\text { interfaces. J. Mol. Biol. 234, 946-950 (1993)._. Medline } & \end{array}$ doi:10.1006/jmbi.1993.1648

14. D. Kuroda, J. J. Gray, Shape complementarity and hydrogen bond preferences in protein-protein interfaces: Implications for antibody modeling and proteinprotein docking. Bioinformatics btw197 (2016). 10.1093/bioinformatics/btw197 Medline doi:10.1093/bioinformatics/btw197

15. P. G. Richardson, P. Sonneveld, M. W. Schuster, D. Irwin, E. A. Stadtmauer, T. Facon, J. L. Harousseau, D. Ben-Yehuda, S. Lonial, H. Goldschmidt, D. Reece, J. F. San-Miguel, J. Bladé, M. Boccadoro, J. Cavenagh, W. S. Dalton, A. L. Boral, D. L. Esseltine, J. B. Porter, D. Schenkein, K. C. Anderson; Assessment of Proteasome Inhibition for Extending Remissions (APEX) Investigators, Bortezomib or high-dose dexamethasone for relapsed multiple myeloma. $N$. Engl. J. Med. 352, 2487-2498 (2005).Medline doi:10.1056/NEJMoa043445

16. Z. Yin, S. J. Patel, W. L. Wang, G. Wang, W. L. Chan, K. R. R. Rao, J. Alam, D. A. Jeyaraj, X. Ngew, V. Patel, D. Beer, S. P. Lim, S. G. Vasudevan, T. H. Keller. Peptide inhibitors of Dengue virus NS3 protease. Part 1: Warhead. Bioorg. Med. Chem. Lett. 16, 36-39 (2006). Medline doi:10.1016/j.bmcl.2005.09.062

17. M. Z. Hammamy, C. Haase, M. Hammami, R. Hilgenfeld, T. Steinmetzer, Development and characterization of new peptidomimetic inhibitors of the West Nile virus NS2B-NS3 protease. ChemMedChem 8, 231-241 (2013)._Medline doi:10.1002/cmdc.201200497

18. T. G. Battye, L. Kontogiannis, O. Johnson, H. R. Powell, A. G. Leslie, iMOSFLM: A new graphical interface for diffraction-image processing with MOSFLM. Acta \begin{tabular}{lllllll}
\hline Crystallogr. D & Biol. Crystallogr. 67, 271-281 (2011).__ Medline
\end{tabular} doi:10.1107/S0907444910048675

19. P. R. Evans, An introduction to data reduction: Space-group determination, scaling and intensity statistics. Acta Crystallogr. D Biol. Crystallogr. 67, 282-292 (2011). Medline doi:10.1107/S090744491003982X

20. P. D. Adams, P. V. Afonine, G. Bunkóczi, V. B. Chen, I. W. Davis, N. Echols, J. J. Headd, L. W. Hung, G. J. Kapral, R. W. Grosse-Kunstleve, A. J. McCoy, N. W. Moriarty, R. Oeffner, R. J. Read, D. C. Richardson, J. S. Richardson, T. C. Terwilliger, P. H. Zwart, PHENIX: A comprehensive Python-based system for macromolecular structure solution. Acta Crystallogr. D Biol. Crystallogr. 66, 213221 (2010). Medline doi:10.1107/S0907444909052925

21. L. Jaroszewski, Z. Li, X. H. Cai, C. Weber, A. Godzik, FFAS server: Novel features and applications. Nucleic Acids Res. 39 (suppl), W38-W44 (2011)._Medline doi:10.1093/nar/gkr441

22. G. N. Murshudov, A. A. Vagin, E. J. Dodson, Refinement of macromolecular structures by the maximum-likelihood method. Acta Crystallogr. D Biol. Crystallogr. 53, 240-255 (1997). Medline doi:10.1107/S0907444996012255 
23. P. Emsley, B. Lohkamp, W. G. Scott, K. Cowtan, Features and development of Coot. Acta Crystallogr. D Biol. Crystallogr. 66, 486-501 (2010). Medline doi:10.1107/S0907444910007493

24. P. Gouet, E. Courcelle, D. I. Stuart, F. Métoz, ESPript: Analysis of multiple sequence alignments in PostScript. Bioinformatics 15, 305-308 (1999). Medline doi:10.1093/bioinformatics/15.4.305

25. U. W. Arndt, R. A. Crowther, J. F. Mallett, A computer-linked cathode-ray tube microdensitometer for x-ray crystallography. J. Sci. Instrum. 1, 510-516 (1968). Medline doi:10.1088/0022-3735/1/5/303

26. M. S. Weiss, R. Hilgenfeld, On the use of the merging $R$ factor as a quality indicator for X-ray data. J. Appl. Cryst. 30, 203-205 (1997). doi:10.1107/S0021889897003907

27. P. A. Karplus, K. Diederichs, Linking crystallographic model and data quality. Science 336, 1030-1033 (2012). Medline doi:10.1126/science.1218231

28. V. B. Chen, W. B. Arendall 3rd, J. J. Headd, D. A. Keedy, R. M. Immormino, G. J. Kapral, L. W. Murray, J. S. Richardson, D. C. Richardson, MolProbity: All-atom structure validation for macromolecular crystallography. Acta Crystallogr. D Biol. Crystallogr. 66, 12-21 (2010). Medline doi:10.1107/S0907444909042073

\section{ACKNOWLEDGMENTS}

We thank S. Zoske and Y. Gül for assistance, S. Anemüller for recording the mass spectra, L. Weigel for the synthesis of precursors of $\mathrm{cn}-716$, and D. Graf for testing this compound for cytotoxicity. We are indebted to the staff of synchrotron beamlines BL 14.1 (BESSY, Berlin) and P11 (DESY, Hamburg) for support. The corresponding coordinates and structure factors are available from the PDB under accession code $5 \mathrm{LCO}$. Funding from the German Center for Infection Research (DZIF-TTU01, grant 8011801911) is gratefully acknowledged. C.D.K. thanks the DFG for financial support (KL-1356/3-1).

\section{SUPPLEMENTARY MATERIALS}

www.sciencemag.org/cgi/content/full/science.aag2419/DC1

Materials and Methods

Figs. S1 to S7

Table S1

References (17-28)

28 May 2016; accepted 30 June 2016

Published online 7 July 2016

10.1126/science.aag2419 


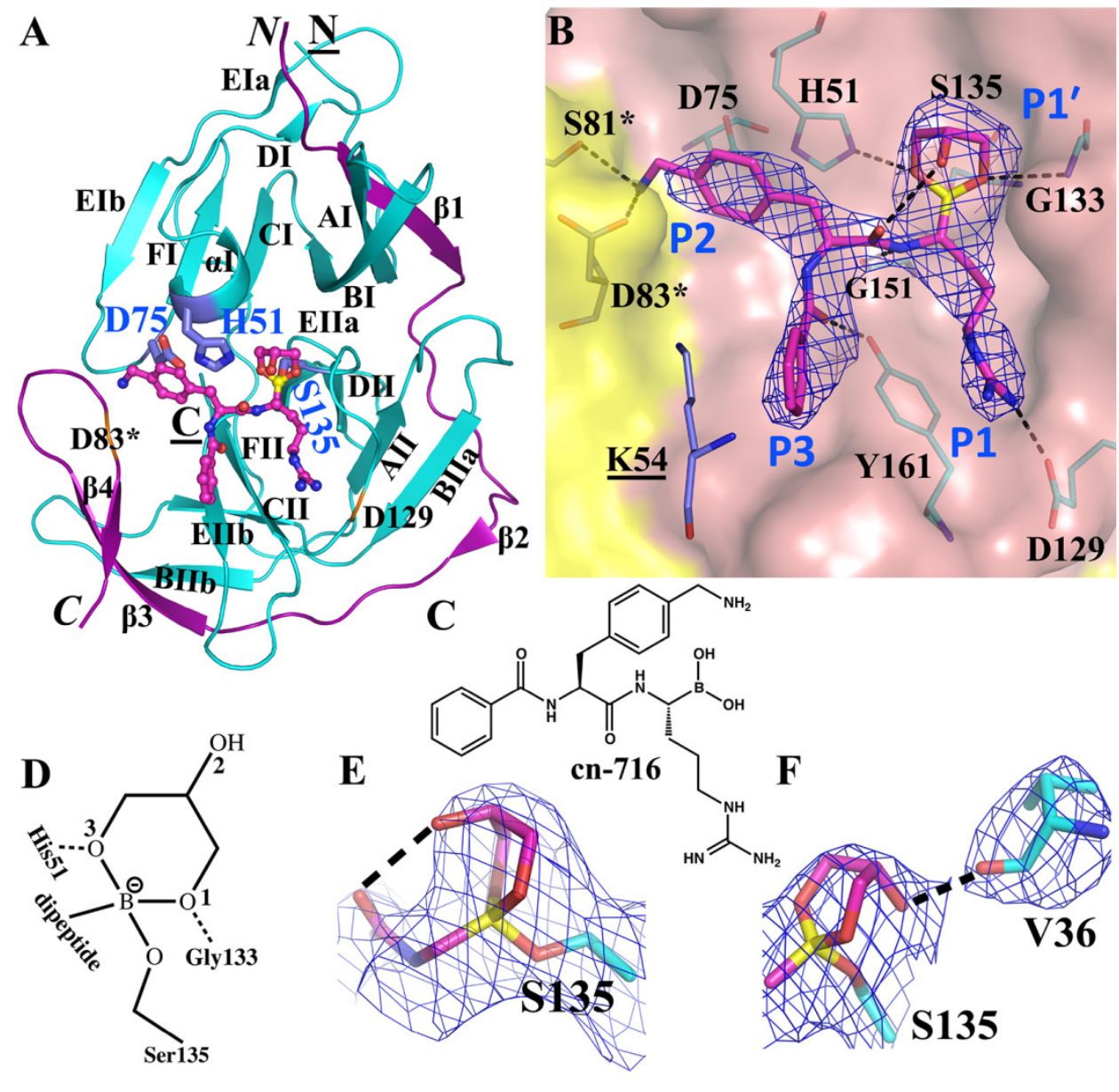

Fig. 1. Crystal structure of the ZIKV NS2B-NS3 ${ }^{\text {pro }}$ monomer in complex with cn-716. (A) Overall structure of the complex. NS3 ${ }^{\text {pro }}$ (cyan) and NS2B (purple) are shown as ribbons, with secondary-structure elements labeled. NS3 ${ }^{\text {pro }}$ is made up by two $\beta$-barrels with strand order $\mathrm{Al}-\mathrm{BI}$ Cl-ol-DI-Ela-Elb-FI and All-BllaBllb-Cll-DII-Ella-Ellb-FII. NS2B includes $\beta$-strands $\beta 1-\beta 4$. The $N$ and $\mathrm{C}$ - termini of NS2B and NS3 $3^{\text {pro }}$ are indicated by letters in italics and non-italics/ underlined, respectively. The inhibitor $\mathrm{cn}-716$ is shown with carbon atoms in purple and boron in yellow. Residues of the catalytic triad are in dark blue. * denotes residues from NS2B. (B) The inhibitor cn716 is embedded in the substratebinding site of ZIKV NS2B-NS3 ${ }^{\text {pro }}$ (same view as in (A)). The surfaces of NS2B and NS3 ${ }^{\text {pro }}$ are yellow and purple, respectively. An $F_{0}-F_{c}$ difference density contoured at $2.5 \sigma$ is shown for cn716. Lys ${ }^{54}$ from molecule $B$ of the dimer interacts with the inhibitor and is indicated by K54. (C) Chemical structure of $\mathrm{cn}-716$. (D) Schematic drawing and $(E), F_{0}-F_{c}$ difference density (2.5 $\sigma$ ) for the cyclic diester and its environment in molecule $A$. (F) Difference density (2.5॰) for the cyclic diester and its environment in molecule B. 


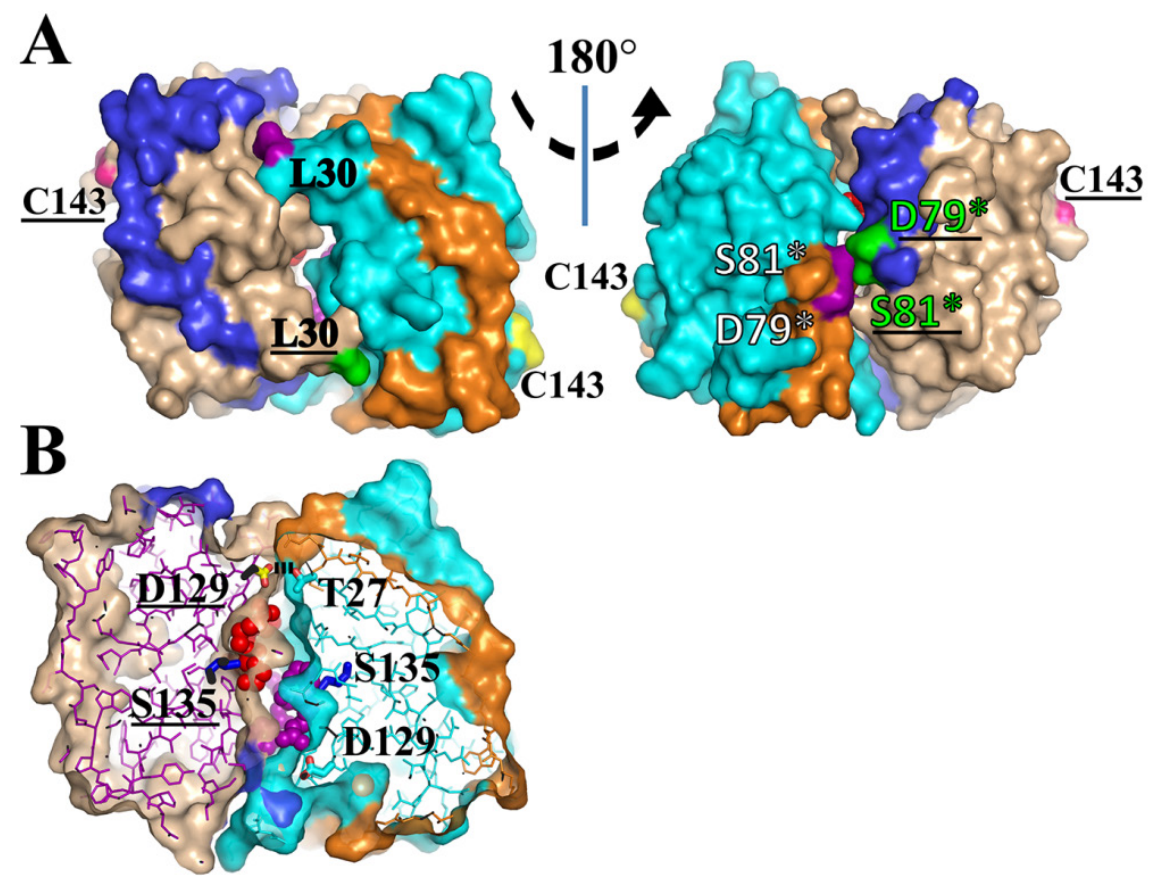

Fig. 2. The tight, noncrystallographic 2:2 dimer of quasi-twofold symmetry formed by the ZIKV NS2B-

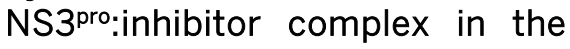
asymmetric unit of the crystal. (A) Front view and back view. The surfaces of NS2B and NS3 ${ }^{\text {pro }}$ of molecule $A$ are shown in cyan and orange, resp., those of molecule $B$ are dark blue and wheat. Labels of molecule $B$ residues are underlined. Residues of NS2B are marked by *. Residues Leu ${ }^{30}$ (purple/green) and Leu ${ }^{31}$ at the tip of the Al-BI loop (Fig. 1A) form a hook making hydrophobic contacts with the opposing monomer. The Cys $^{143}$ residues forming labile disulfide bonds in the SS-dimer are yellow and pink. (B) A slice through the interior of the dimer, showing the S135 side-chains (blue) covalently bound to the inhibitor molecules. The color code is the same as in (A). Inhibitor molecules are colored purple and red. See fig. S5 for a schematic illustration of the interactions across the dimer interface. 
Table 1. Kinetic parameters of variants of ZIKV NS2B-NS3 protease, in comparison to a similar WNV NS2B-NS3 ${ }^{\text {pro }}$ construct. Data are for the cleavage of the flavivirus protease substrate Bz-Nle-Lys-Lys-Arg-AMC. "Monomer (wt)" [See supplementary materials (p. 4) for details, including definition of "wt" (p. 2)] and "SS-dimer (wt)" indicate enzyme preparations corresponding to the monomer (in the presence of TCEP) and the SS-dimer fraction from gel permeation chromatography. The kinetic parameters for the ZIKV protease with Asp ${ }^{83}$ * replaced by Asn are also included. "WNV NS2B-NS3 ${ }^{\text {pro }}$ (wt)" is our recombinant preparation of the WNV protease. For comparison, the $k_{\text {cat }} / K_{\mathrm{m}}$ values for WNV and DENV-2 NS2B-NS3 ${ }^{\text {pro }}$ and with the substrate Bz-Nle-Lys-Arg-Arg-AMC reported in (6) are given. (dash indicates not reported). All values in this table are obtained at $\mathrm{pH} 8.5$.

\begin{tabular}{|c|c|c|c|}
\hline Protease & $k_{\text {cat }}\left(s^{-1}\right)$ & $K_{\mathrm{m}}(\mu \mathrm{M})$ & $k_{\text {cat }} / K_{\mathrm{m}}\left(\mathrm{s}^{-1} \mathrm{M}^{-1}\right)$ \\
\hline \multicolumn{4}{|l|}{ ZIKV NS2B-NS3 ${ }^{\text {pro }}$} \\
\hline Monomer (wt) & $44.6 \pm 1.0$ & $18.3 \pm 1.6$ & $2,440,000 \pm 215,000$ \\
\hline SS-dimer (wt) & $28.5 \pm 0.6$ & $5.9 \pm 0.5$ & $4,850,000 \pm 429,000$ \\
\hline Cys ${ }^{80}$ Ser $/$ Cys $1^{43}$ Ser & $28.8 \pm 0.5$ & $5.1 \pm 0.5$ & $5,620,000 \pm 546,000$ \\
\hline $\mathrm{Asp}^{83 *}$ Asn (monomer) & $38.5 \pm 1.4$ & $35.3 \pm 4.2$ & $1,091,000 \pm 136,000$ \\
\hline \multicolumn{4}{|l|}{ WNV NS2B-NS3 ${ }^{\text {pro }}$} \\
\hline wt & $8.7 \pm 0.1$ & $77.4 \pm 3.6$ & $112,000 \pm 5000$ \\
\hline wt (6) & - & - & $37,000 \pm 7000$ \\
\hline \multicolumn{4}{|l|}{ DENV-2 NS2B-NS3 ${ }^{\text {pro }}$} \\
\hline wt (6) & - & - & $30,000 \pm 7000$ \\
\hline
\end{tabular}


EXTENDED PDF FORMAT

\section{Science \\ MIAAAS}

Crystal structure of Zika virus NS2B-NS3 protease in complex with a boronate inhibitor

Jian Lei, Guido Hansen, Christoph Nitsche, Christian D. Klein, Linlin

Zhang and Rolf Hilgenfeld (July 7, 2016)

published online July 7, 2016

Editor's Summary

This copy is for your personal, non-commercial use only.

Article Tools Visit the online version of this article to access the personalization and article tools:

http://science.sciencemag.org/content/early/2016/07/06/science.aag2419

Permissions Obtain information about reproducing this article:

http://www.sciencemag.org/about/permissions.dtl

Science (print ISSN 0036-8075; online ISSN 1095-9203) is published weekly, except the last week in December, by the American Association for the Advancement of Science, 1200 New York Avenue NW, Washington, DC 20005. Copyright 2016 by the American Association for the Advancement of Science; all rights reserved. The title Science is a registered trademark of AAAS. 